\title{
Review
}

\section{Stating the obvious: intravenous magnesium sulphate should be the first parenteral bronchodilator in paediatric asthma exacerbations unresponsive to first-line therapy}

What is the most appropriate second-line intravenous bronchodilator treatment when a child with a severe asthma attack is not responsive to initial inhaled therapy? The second-line treatment options for acute asthma include parenteral $\beta_{2}$-agonists, methylxanthine and magnesium sulphate $\left(\mathrm{MgSO}_{4}\right)$. There is a poor evidence-base to inform this decision. This review argues that intravenous $\mathrm{MgSO}_{4}$ is the obvious treatment of choice for this situation as the initial treatment based on current knowledge. We describe the mode of action, scope and limitations of $\mathrm{MgSO}_{4}$, safety profile, economic impact, comparisons of the alternatives, and finally, what the guidelines say. This review explores the suitability of intravenous $\mathrm{MgSO}_{4}$ as a pragmatic and safe initial second-line therapy for children unresponsive to initial asthma management.

\section{Introduction}

Acute exacerbation or "attacks" of asthma pose a significant burden to paediatric healthcare facilities and to patients and their families. Despite a consensus on the fundamental principles underpinning the management of an acute asthma exacerbation, considerable variations exist in the "second-line approach" recommendations in guidelines once initial inhaled bronchodilators and corticosteroids have not worked [1-4]. Most second-line treatment options for acute asthma include parenteral $\beta_{2}$-agonists, methylxanthine and magnesium sulphate $\left(\mathrm{MgSO}_{4}\right)[5-8]$. There are few clinical trials comparing their relative efficacy and safety profiles [9]. This paucity of evidence can potentially lead to a clinical dilemma for the treating physician on selecting a safe and effective initial second-line agent in children unresponsive to the initial conventional approach.

With ever-increasing pressures on healthcare facilities, an ideal step-up treatment should be safe and effective with minimal resource implications. The traditional agents used in asthma escalation, such as parenteral $\beta_{2}$-agonists and aminophylline, are known to require complex calculations for rate and dilution and the need for high-dependency monitoring [1-4].

$\mathrm{MgSO}_{4}$ has a distinct mechanism of action in acute asthma, and has been a subject of interest in research for well over half a century. $\mathrm{MgSO}_{4}$ can be administered through inhalational and intravenous

@ERSpublications

In acute asthma in children, when they are not responsive to maximal inhaled therapy, intravenous magnesium sulphate should be the first choice second-line intravenous treatment. https://bit.ly/3lvmH08

Cite as: Erumbala G, Anzar S, Tonbari A, et al. Stating the obvious: intravenous magnesium sulphate should be the first parenteral bronchodilator in paediatric asthma exacerbations unresponsive to first-line therapy. Breathe 2021; 17 : 210113.

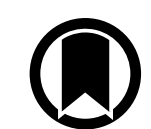

CrossMark 
routes. Inhaled $\mathrm{MgSO}_{4}$ has been shown to be effective as an adjuvant therapy to standard management [10], although more recent data suggest it has little effect on length of stay and admission [11]. On its own, however, it has a limited utility in improving lung function and reducing hospital admissions [12]. Intravenous administration of $\mathrm{MgSO}_{4}$ can improve clinical outcomes without significant safety concerns and resource implications. This review explores the suitability of intravenous $\mathrm{MgSO}_{4}$ as a pragmatic and safe initial second-line therapy for children unresponsive to initial asthma management.

\section{$\mathrm{MgSO}_{4}$ in acute asthma: mechanism of action}

Acute asthma exacerbation is associated with reversible obstruction of the airways through a complex interplay of bronchoconstriction, inflammation of the airways and increased mucus production. $\mathrm{MgSO}_{4}$ exerts its beneficial effects at multiple levels in the inflammatory cascade of acute asthma. The bronchodilator effects of $\mathrm{MgSO}_{4}$ are attributed to the blockade of calcium channels in the airway smooth muscles and a reduction in airway excitability. Furthermore, $\mathrm{MgSO}_{4}$ exerts an antiinflammatory effect through several mechanisms, including the obliteration of the release of oxygen free radicals, stabilisation of T-cells and mast cells, and facilitating the release of endogenous nitric oxide and prostacyclins. A synergistic bronchodilator action, when used simultaneously with salbutamol, has also been proposed [13, 14].

The usual recommended bolus dose of intravenous $\mathrm{MgSO}_{4}$ is 25-50 mg $\mathrm{kg}^{-1}$ (maximum $2 \mathrm{~g}$ ) [15], but higher doses of $50-75 \mathrm{mg} \cdot \mathrm{kg}^{-1}$ have also been proposed to achieve therapeutic drug levels [16].

\section{$\mathrm{MgSO}_{4}$ as the first parenteral bronchodilator: scope and limitations}

There is a scarcity of adequately designed and powered trials that compare the efficacy and safety of intravenous $\mathrm{MgSO}_{4}$ with other parenteral bronchodilators in acute asthma. The available evidence is further marred by a lack of uniformity in the use of clinical rating scales and other outcome parameters [17]. The bulk of evidence on intravenous $\mathrm{MgSO}_{4}$ hence stems from observational studies and a limited number of placebo-controlled studies.

\section{Impact of the use of intravenous $\mathrm{MgSO}_{4}$ on patient outcome and organisational burden}

Trials using intravenous $\mathrm{MgSO}_{4}$ as a second-line agent in acute asthma generally favour its early use.
Pooled results from randomised controlled trials with a total of 425 children comparing $\mathrm{MgSO}_{4}$ with placebo or other parenteral agents demonstrated that the use of parenteral $\mathrm{MgSO}_{4}$ resulted in significant benefits with clinical improvement, need for hospitalisation or mechanical ventilation, and discharge from the emergency department [18]. Notable caveats in interpreting these trials were smaller sample sizes and variable outcome parameters. This finding is consistent with an earlier meta-analysis on $\mathrm{MgSO}_{4}$ treatment in emergency department settings [19], where concurrent use of $\mathrm{MgSO}_{4}$ intravenously with inhaled bronchodilators and systemic corticosteroids resulted in an improvement in clinical scores. Thus, it appears that early use of intravenous $\mathrm{MgSO}_{4}$ could compliment the bronchodilator response to the first-line agents.

Two systematic reviews illustrated the unequivocal benefit of intravenous $\mathrm{MgSO}_{4}$ in improving spirometry parameters and hospital admission rates in the paediatric age group [12, 20], but not with nebulised $\mathrm{MgSO}_{4}$. A Cochrane review by GRIFFITHS et al. [21] investigating the effect of intravenous $\mathrm{MgSO}_{4}$ on hospitalisation rates as the primary outcome serves as a further testament, with a reduced odds for admission of $68 \%$ with intravenous $\mathrm{MgSO}_{4}$

Mechanical ventilation in status asthmaticus is challenging and is reserved for patients who fail to respond to optimal medical management and develop respiratory failure. ToRREs et al. [22] reported a marked reduction in mechanical ventilation requirements for children with acute asthma exacerbation who received intravenous $\mathrm{MgSO}_{4}$ within the first hour of treatment in the emergency department compared with those who only received standard care (nebulisation with $\beta_{2}$-agonists and corticosteroids). This study is interesting but has potential flaws. It was an open study and thus not blinded and in the control group there was a 33\% intubation rate, which is extremely high. Considering the significant impact that mechanical ventilation has on the patient and hospital resources, these results could imply a potential significant saving of resources and reduced impact on the child.

A recent open intervention study with intravenous $\mathrm{MgSO}_{4}$ alone given to all the subjects presenting with acute asthma exacerbation before receiving nebulised bronchodilators or steroids demonstrated a significant improvement in lung function parameters [23]. These findings indicate that intravenous $\mathrm{MgSO}_{4}$ has bronchodilator properties even when used as a sole agent in the initial management of asthma.

High-dose continuous infusions of $\mathrm{MgSO}_{4}$ have been used in the emergency department. This approach appears to have an effect on earlier discharge from the emergency department. In an open label, randomised, prospective study of 38 children (aged 6-16 years) in a single centre study from Paraguay, $50 \mathrm{mg} \cdot \mathrm{kg}^{-1}$ over $1 \mathrm{~h}$ (bolus) was compared with high-dose prolonged $\mathrm{MgSO}_{4}$ 
infusion of $50 \mathrm{mg} \cdot \mathrm{kg}^{-1} \cdot \mathrm{h}^{-1}$ for $4 \mathrm{~h}$ (maximum of $8000 \mathrm{mg}$ per $4 \mathrm{~h}$ ) [24]. 47\% in high-dose prolonged $\mathrm{MgSO}_{4}$ infusion group (nine out of 19 ) versus $10 \%$ (two out of 21) in the bolus group ( $p=0.032)$ were discharged at $24 \mathrm{~h}$, with an absolute risk reduction of $37 \%(95 \% \mathrm{Cl} 10-63)$ and a number needed to treat of $2.7(95 \% \mathrm{Cl} 1.6-9.5)$ to facilitate a discharge at or before $24 \mathrm{~h}$. The length of stay was shorter in the high-dose prolonged $\mathrm{MgSO}_{4}$ infusion group (mean $\pm \mathrm{SD}$ : high-dose prolonged $\mathrm{MgSO}_{4}$ infusion, $34.13 \pm 19.54 \mathrm{~h}$; bolus, $48.05 \pm 18.72 \mathrm{~h} ; \mathrm{p}=0.013$; $95 \% \mathrm{Cl}, 1.3-26.5)$ [24]. This is interesting data but has not been compared head-to-head with other regimens and so the exact role of high-dose continuous infusions of $\mathrm{MgSO}_{4}$ in the emergency department is unclear.

\section{Does the early use of intravenous $\mathrm{MgSO}_{4}$ in the emergency department reduce the chances of hospitalisation?}

An analysis of the Cochrane reviews on randomised controlled trials looking at the efficacy and safety of second-line agents used in acute asthma escalation regimes covering 67 trials unequivocally established that the use of intravenous $\mathrm{MgSO}_{4}$ reduced chances, as well as the duration, of hospitalisation (high certainty evidence) [9]. The review did not identify any second-line interventions that could reduce the chances of critical care admission. Another systematic review [25] also inferred that a dose of intravenous $\mathrm{MgSO}_{4}$ at $50-75 \mathrm{mg} \cdot \mathrm{kg}^{-1}$ in emergency departments reduced the chance of hospital admission, with one hospitalisation prevented for every five children receiving the dose. A metaanalysis [19] of five randomised placebo-controlled trials also demonstrated that administration of intravenous $\mathrm{MgSO}_{4}$ reduced the hospitalisation rates with a number needed to treat of four patients.

\section{The safety profile of intravenous $\mathrm{MgSO}_{4}$}

A review of 53 papers on the use of intravenous $\mathrm{MgSO}_{4}$ in asthma in the emergency room did not highlight any safety concerns [25]. Furthermore, the use of $\mathrm{MgSO}_{4}$ did not produce any haemodynamic or neuromuscular problems even at extended dose regimes that included a bolus followed by an infusion over $4 \mathrm{~h}$ [26]. The wide therapeutic window and safety profile of intravenous $\mathrm{MgSO}_{4}$ is further affirmed by a retrospective study of children who received prolonged $\mathrm{MgSO}_{4}$ infusions for more than $24 \mathrm{~h}$ [27].

\section{Is monitoring of serum levels needed?}

The recommended dose of $\mathrm{MgSO}_{4}$ is $25-50 \mathrm{mg} \cdot \mathrm{kg}^{-1}$ per dose (maximum $2 \mathrm{~g}$ ) [15]. After the loading dose, the serum $\mathrm{MgSO}_{4}$ levels have been examined in several studies; adverse effects tend to occur at levels exceeding $9 \mathrm{mg} \cdot \mathrm{dL}^{-1}$. Significant untoward events such as respiratory depression and arrhythmia occur with serum levels exceeding $12 \mathrm{mg} \cdot \mathrm{dL}^{-1}$. The maximum 1-h post-dose serum levels attained after a bolus of up to $20 \mathrm{~g}$ in adults have been shown to be three times the normal serum levels (normal range 1.7-2.2 $\mathrm{mg} \cdot \mathrm{dL}^{-1}$ ) [28]. lonised $\mathrm{MgSO}_{4}$ levels are regarded as superior in ascertaining the correlation with the bronchodilator effects. The exact correlation between the ionised and total serum levels is poorly understood and is likely influenced by the blood $\mathrm{pH}$. Due to this, serum $\mathrm{MgSO}_{4}$ level estimation is not routinely recommended with bolus dose regimes [27].

\section{The financial impact of the addition of intravenous $\mathrm{MgSO}_{4}$}

A cost-utility analysis comparing the economic burden of adding intravenous $\mathrm{MgSO}_{4}$ to the standard treatment (salbutamol nebulisation and methylprednisolone) observed the use of the former offered superior cost-efficiency when compared to the latter. The authors recommended the inclusion of $\mathrm{MgSO}_{4}$ in acute asthma management protocols, especially in middle-income countries [29].

\section{Second-line agents in acute asthma management: weighing up the options}

Acute asthma protocols use intravenous $\beta_{2}$-agonists, aminophylline or $\mathrm{MgSO}_{4}$ when the response to firstline treatment is suboptimal [1-4]. In a randomised controlled trial that compares these second-line approaches, SINGHI et al. [30] compared the 1-h post-treatment Clinical Asthma Severity (CAS) scores in 100 children whose clinical condition mandated $\mathrm{MgSO}_{4}$, terbutaline or aminophylline, administered intravenously. The authors observed that intravenous $\mathrm{MgSO}_{4}$, used as an adjuvant to inhaled $\beta_{2}$-agonists and corticosteroids, was more efficacious and safer than terbutaline or aminophylline. No adverse effects were reported in children who received $\mathrm{MgSO}_{4}$, while hypokalaemia and vomiting were reported in some children with terbutaline and aminophylline, respectively. Notwithstanding the possible impacts of a small sample, lack of double-blinding and interobserver variability in clinical scoring, this trial places intravenous $\mathrm{MgSO}_{4}$ as a reasonable first option when conventional nebulisation and corticosteroids fail. A previous smaller trial [31] compared intravenous $\mathrm{MgSO}_{4}$ and salbutamol in a critical care environment. Both the agents produced discernible improvement in the clinical picture, albeit the latter faring slightly better.

Aminophylline has a narrow therapeutic range, mandating careful balancing of dosing to optimise 
the therapeutic benefits while avoiding adverse effects. Attaining serum levels within this desired range can be challenging, as drug elimination rates can vary between individuals [32]. Emesis is a common side-effect, while a reduction in seizure threshold is reported even with therapeutic serum levels [33]. Confusion, neurological depression, dysrhythmias and alteration of hepatic function are known to occur with blood levels exceeding the therapeutic range.

Intravenous salbutamol is preferred by some as the standard escalation agent for acute asthma. There is an absence of standard recommendations on the use of nebulised bronchodilators alongside its intravenous use. Markedly elevated salbutamol concentrations have been reported in children who have received intravenous salbutamol at the currently recommended doses. Common adverse events include anxiety, tremors, lactic acidosis, hypokalaemia, raised blood sugar and sinus tachycardia, which can also be associated with clinical deterioration, thus resulting in a potentially confusing picture for the clinician. In addition, the drug levels that can be associated with these sideeffects are not clear [34]. An alternate $\beta_{2}$-agonist often employed parenterally in acute asthma is terbutaline. Its use has been associated with severe sympathomimetic effects such as tachycardia, arrhythmia, and myocardial ischaemia [17].

\section{Intravenous $\mathrm{MgSO}_{4}$ in the acute asthma treatment hierarchy: current guidelines and practices}

The British Thoracic Society/Scottish Intercollegiate Guidelines Network (UK 2019) recommends $\mathrm{MgSO}_{4}$ as the first-line intravenous agent in children failing to respond to nebulised bronchodilators [1]. A bolus dose of salbutamol may also be considered early. Aminophylline is recommended only when other treatment approaches are exhausted [1]. The Australian Asthma Council also propose intravenous $\mathrm{MgSO}_{4}$ as the preferred intravenous second-line agent in severe/life-threatening asthma, with intravenous salbutamol and aminophylline recommended as third-line agents [2]. The Canadian Paediatric Society position statement also makes similar recommendations on $\mathrm{MgSO}_{4}$ and salbutamol use, with aminophylline reserved for critical care settings [3]. This standpoint on the use of $\mathrm{MgSO}_{4}$ is shared by the Global Initiative for Asthma (GINA), which does not approve the use of aminophylline for safety concerns, and limits the use of terbutaline for very unwell children with respiratory effort inadequate to deliver nebulised bronchodilator [4]. The New Zealand Asthma and Respiratory Foundation guidelines extend the use of intravenous $\mathrm{MgSO}_{4}$ to pre-hospital settings [35].
A recent Paediatric Emergency Care Applied Research Network (PECARN) registry review noted the use of intravenous $\mathrm{MgSO}_{4}$ is in around $10 \%$ of children presenting with acute asthma, with the median time from triage to administration around $2.5 \mathrm{~h}$. A discharge from the emergency department after intravenous $\mathrm{MgSO}_{4}$ was deemed safe [36]. The acceptance of intravenous $\mathrm{MgSO}_{4}$ is again reflected in a nationwide survey from the Netherlands, where $96 \%$ of the respondents reported its use in children who failed to respond to first-line asthma therapy [37]. Perhaps the most telling evidence of the increasing recognition of intravenous $\mathrm{MgSO}_{4}$ in status asthmaticus is that its use has almost doubled across children's units across the USA over the past decade [38]. A concurrent reduction in the length of hospital stay, from 1.6 days in 2010 to 1.4 days in 2017 , was also noted in this review.

\section{Conclusion}

The choice of the escalation agent in acute asthma management often remains obscure, with a range of options and widespread variability in emergency practice. Evidence pooled in this review indicates that the early use of intravenous $\mathrm{MgSO}_{4}$ in acute asthma management when conventional inhaled bronchodilators fail is beneficial in improving the clinical course and reducing hospitalisation. The lack of special clinical and pharmacokinetic monitoring requirements puts this drug in a uniquely advantageous position over intravenous $\beta_{2}$-agonists or methylxanthine. The safety profile of intravenous $\mathrm{MgSO}_{4}$ also appears to be distinctly superior compared with the other agents. However, there is a distinct shortage of well-powered studies with robust designs comparing the clinical efficacy and impact on hospital resources. The bulk of current evidence is constituted by studies examining the safety and efficacy of individual agents and based on this, the authors conclude that intravenous $\mathrm{MgSO}_{4}$ should be the answer to the "escalation dilemma" in acute asthma management in children.

The final conclusions of the paper by NEAME et al. [33], on which intravenous bronchodilator to choose, gave simple pragmatic advice: "Decisions about which treatment to use should include risk management considerations such as ease of prescription, preparation and administration factors and availability of high-dependency beds". We would agree with this and argue that $\mathrm{MgSO}_{4}$ should be the initial second-line intravenous medication to use once maximal inhaled therapy has failed. Intravenous $\mathrm{MgSO}_{4}$ is easy to prepare and administer, has the best side-effect protocol (compared to the other intravenous bronchodilator options), does not need serum drug level monitoring, does not require admission to a paediatric high-dependency unit/paediatric 
intensive care unit to give $[5,6]$, and, once the emergency department team are experienced with $\mathrm{MgSO}_{4}$ delivery, is a safe initial intravenous option.
Until an adequately powered head-to-head trial shows superiority of any of the other intravenous bronchodilators, $\mathrm{MgSO}_{4}$ is the obvious choice.

\section{Affiliations}

Gokul Erumbala'1, Sabu Anzar' ${ }^{1}$, Amjad Tonbari' ${ }^{1}$ Ramadan Salem ${ }^{1}$, Colin Powell1,2

${ }^{1}$ Pediatric Emergency Dept, Sidra Medicine, Doha, Qatar. ${ }^{2}$ Division of Population Medicine, School of Medicine, Cardiff University, Cardiff, UK.

\section{Conflict of interest}

G. Erumbala has nothing to disclose. S. Anzar has nothing to disclose. A. Tonbari has nothing to disclose. R. Salem has nothing to disclose. C. Powell is an Assistant Editor of Archives of Disease in Childhood; reports participation on a Data Safety Monitoring Board or Advisory Board for BRACE study (Australia; Chair) and PARROT study (Liverpool and Australia; Chair).

\section{References}

1. British Thoracic Society, Scottish Intercollegiate Guidelines Network. SIGN158 British guideline on the management of asthma. Revised edition published July 2019. https://www. brit-thoracic.org.uk/document-library/guidelines/asthma/ btssign-guideline-for-the-management-of-asthma-2019/

2. National Asthma Council Australia. Australian Asthma Handbook - Quick Reference Guide, Version 2.1. Melbourne, National Asthma Council Australia, 2020. www. asthmahandbook.org.au

3. Trottier ED, Chan K, Allain D, et al. Position statement: Managing an acute asthma exacerbation in children. Canadian Paediatric Society, 2021. https://cps.ca/en/documents/ position/managing-an-acute-asthma-exacerbation

4. Global Initiative for Asthma. Global Strategy for Asthma Management and Prevention. https://ginasthma.org/

5. Lyttle MD, O'Sullivan R, Doull I, et al. Variation in treatment of acute childhood wheeze in emergency departments of the United Kingdom and Ireland: an international survey of clinician practice. Arch Dis Child 2015; 100: 121-125.

6. Morris I, Lyttle MD, O'Sullivan R, et al. Which intravenous bronchodilators are being administered to children presenting with acute severe wheeze in the UK and Ireland? Thorax 2015; 70: 88-91.

7. Biagini Myers JM, Simmons JM, Kercsmar CM, et al. Heterogeneity in asthma care in a statewide collaborative: the ohio pediatric asthma repository. Pediatrics 2015; 135 : 271-279.

8. Fishe JN, Palmer E, Finlay E, et al. A statewide study of the epidemiology of emergency medical services' management of pediatric asthma. Pediatr Emerg Care 2021; 37: 560-569.

9. Craig SS, Dalziel SR, Powell CV, et al. Interventions for escalation of therapy for acute exacerbations of asthma in children: an overview of Cochrane Reviews. Cochrane Database Syst Rev 2020; 8: CD012977.

10. Powell CV, Kolamunnage-Dona R, Lowe J, et al. MAGNEsium Trial In Children (MAGNETIC): a randomised, placebocontrolled trial and economic evaluation of nebulised $\mathrm{MgSO}_{4}$ in acute severe asthma in children. Health Technol Assess 2013; 17: v-vi, 1-216.

11. Schuh S, Sweeney J, Rumantir M, et al. Effect of nebulized magnesium vs placebo added to albuterol on hospitalization among children with refractory acute asthma treated in the emergency department: a randomized clinical trial. JAMA 2020; 324: 2038-2047.

12. Su Z, Li R, Gai Z. Intravenous and nebulized magnesium sulfate for treating acute asthma in children: a systematic review and meta-analysis. Pediatr Emerg Care 2018; 34: 390-395.

13. Aniapravan R, Pullattayil A, Al Ansari K, et al. Question 5 : $\mathrm{MgSO}_{4}$ for acute asthma in children. Paediatr Respir Rev 2020; 36: 112-117.
14. Ohn M, Jacobe S. Magnesium should be given to all children presenting to hospital with acute severe asthma. Paediatr Respir Rev 2014; 15: 319-321.

15. Nievas IF, Anand KJ. Severe acute asthma exacerbation in children: a stepwise approach for escalating therapy in a pediatric intensive care unit. J Pediatr Pharmacol Ther 2013; 18: 88-104.

16. Rower JE, Liu X, Yu T, et al. Clinical pharmacokinetics of magnesium sulfate in the treatment of children with severe acute asthma. EurJ Clin Pharmacol 2017; 73: 325-331.

17. Lee MO, Sivasankar S, Pokrajac N, et al. Emergency department treatment of asthma in children: a review. J Am Coll Emerg Physicians Open 2020; 1: 1552-1561.

18. Liu X, Yu T, Rower JE, et al. Optimizing the use of intravenous magnesium sulfate for acute asthma treatment in children. Pediatr Pulmonol 2016; 51: 1414-1421.

19. Cheuk DK, Chau TC, Lee SL. A meta-analysis on intravenous $\mathrm{MgSO}_{4}$ for treating acute asthma. Arch Dis Child 2005; 90 : 74-77.

20. Mohammed S, Goodacre S. Intravenous and nebulised $\mathrm{MgSO}_{4}$ for acute asthma: systematic review and meta-analysis. Emerg Med J 2007; 24: 823-830.

21. Griffiths B, Kew KM, Normansell R. Intravenous magnesium sulfate for treating children with acute asthma in the emergency department. Paediatr Respir Rev 2016; 20: 45-47.

22. Torres S, Sticco N, Bosch JJ, et al. Effectiveness of magnesium sulfate as initial treatment of acute severe asthma in children, conducted in a tertiary-level university hospital: a randomized, controlled trial. Arch Argent Pediatr 2012; 110: 291-296.

23. Özdemir A, Doğruel D. Efficacy of magnesium sulfate treatment in children with acute asthma. Med Princ Pract 2020; 29: 292-298.

24. Irazuzta JE, Paredes F, Pavlicich V, et al. High-dose magnesium sulfate infusion for severe asthma in the emergency department: efficacy study. Pediatr Crit Care Med 2016; 17: e29-e33.

25. Irazuzta JE, Chiriboga N. Magnesium sulfate infusion for acute asthma in the emergency department. J Pediatr (Rio J) 2017; 93: Suppl. 1, 19-25

26. Irazuzta J, Egelund T, Wassil SK, et al. Feasibility of short-term infusion of magnesium sulfate in pediatric patients with status asthmaticus. J Pediatr Pharmacol Ther 2012; 17: 150-154.

27. Graff DM, Stevenson MD, Berkenbosch JW. Safety of prolonged magnesium sulfate infusions during treatment for severe pediatric status asthmaticus. Pediatr Pulmonol 2019; 54: 1941-1947.

28. Sydow M, Crozier TA, Zielmann S, et al. High-dose intravenous magnesium sulfate in the management of life-threatening status asthmaticus. Intensive Care Med 1993; 19: 467-471.

29. Buendia JA, Acuña-Cordero R, Rodriguez-Martinez CE. The cost-utility of intravenous magnesium sulfate for treating 
asthma exacerbations in children. Pediatr Pulmonol 2020 . 55: 2610-2616.

30. Singhi S, Grover S, Bansal A, et al. Randomised comparison of intravenous $\mathrm{MgSO}_{4}$, terbutaline and aminophylline for children with acute severe asthma. Acta Paediatr 2014; 103 : 1301-1306.

31. Santana JC, Barreto SS, Piva JP, et al. Estudo controlado do uso endovenoso de sulfato de magnésio ou de salbutamol no tratamento precoce da crise de asma aguda grave em crianças [Randomized clinical trial of intravenous magnesium sulfate versus salbutamol in early management of severe acute asthma in children]. J Pediatr (Rio J) 2001; 77: 279-287

32. Cooney L, Sinha I, Hawcutt D. Aminophylline dosage in asthma exacerbations in children: a systematic review. PLoS One 2016 11: e0159965.

33. Neame M, Aragon O, Fernandes RM, et al. Salbutamol or aminophylline for acute severe asthma: how to choose which one, when and why? Arch Dis Child Educ Pract Ed 2015; 100: 215-222.

34. Starkey ES, Mulla H, Sammons HM, et al. Intravenous salbutamol for childhood asthma: evidence-based medicine? Arch Dis Child 2014; 99: 873-877.

35. Asher I, McNamara D, Davies C, et al. Asthma and Respiratory Foundation NZ child and adolescent asthma guidelines: a quick reference guide. N Z Med J 2017; 130: 10-33.

36. Johnson MD, Zorc JJ, Nelson DS, et al. Intravenous magnesium in asthma pharmacotherapy: variability in use in the PECARN registry. J Pediatr 2020; 220: 165-174.e2.

37. van Weelden $\mathrm{M}$, van Ewijk BE, Plötz FB. Intravenous $\mathrm{MgSO}_{4}$ in children with acute wheeze: a nationwide survey. J Asthma 2021; 58: 1444-1450.

38. Mittal V, Hall M, Antoon J, et al. Trends in intravenous magnesium use and outcomes for status asthmaticus in children's hospitals from 2010 to 2017. J Hosp Med 2020; 15: 403-406 